\title{
The ecology of drought - a workshop report
}

\section{AUTHORS: \\ Anthony M. Swemmer ${ }^{1}$ \\ William J. Bond ${ }^{1,2}$ (iD \\ Jason Donaldson ${ }^{3}$ (D \\ Gareth P. Hempson ${ }^{1}$ (DD \\ Johan Malherbe ${ }^{4}$ (ID \\ Izak P.J. Smit ${ }^{3,5}$ (iD)}

\section{AFFILIATIONS:}

${ }^{1}$ South African Environmental Observation Network,

Phalaborwa, South Africa

2Department of Biological

Sciences, University of

Cape Town, Cape Town, South Africa

${ }^{3}$ School of Animal, Plant and Environmental Sciences,

University of the Witwatersrand, Johannesburg, South Africa

${ }^{4}$ Natural Resources and

the Environment, Council for Scientific and Industrial Research, Pretoria, South Africa ${ }^{5}$ South African National Parks, Skukuza, South Africa

\section{CORRESPONDENCE TO:}

Anthony Swemmer

EMAIL:

tony@saeon.ac.za

\section{KEYWORDS:}

climatology; herbivory; mortality; resilience; vegetation

\section{HOW TO CITE: \\ Swemmer AM, Bond WJ, Donaldson J, Hempson \\ GP, Malherbe J, Smit IPJ. The ecology of drought - a workshop report. S Afr J Sci. 2018;114(9/10), Art. \#5098, 3 pages. https://doi. org/10.17159/sajs.2018/5098}

\section{PUBLISHED:}

11 September 2018

\author{
(C) 2018. The Author(s). \\ Published under a Creative \\ Commons Attribution Licence.
}

The 2014-2016 drought experienced across the summer rainfall region of South Africa brought a range of social and economic impacts, with regular coverage in the public media. However, little has been reported on the ecological impacts of the drought in the rural rangelands and protected areas of the country. To address this issue a workshop on the ecology of drought was organised by the South African Environmental Observation Network (SAEON), a facility of the National Research Foundation, in November 2017. The event brought together researchers active in savannas (bushveld) of the northeastern part of the country, including the Kruger National Park (KNP) and adjacent Lowveld, and in savannas and grasslands of KwaZulu-Natal. The land uses in these areas varied from conservation to densely populated communal rangelands.

Drought impacts on commercial farmers are relatively straightforward to assess through quantification of crop yields. Ecological impacts are less tangible, particularly as many of these may only manifest years after the drought has ceased. Furthermore, while drought impacts are invariably negative in agriculture, they may have some positive impacts in ecosystems, such as reducing herbivore numbers (thus preventing overgrazing in the long term), reducing the densities of trees (thus combating bush encroachment) and providing an opportunity for 'drought adapted' flora and fauna to thrive. The primary aim of the workshop was to assess evidence available for testing the divergent predictions of drought impacts on natural systems. A key question was how severely livestock and wildlife populations were affected. On the topic of vegetation, some argued that droughts open up savannas by killing trees, others that droughts promote the seedling recruitment of trees (as a consequence of reduced competition from grasses and less fire) leading to bush encroachment. Many questions exist around recovery following the drought. Some argued that grasses take decades to recover their productive potential, others that recovery is very rapid once the drought breaks. How does the pattern of recovery vary with the ecological status preceding droughts and actions after it? And, most ominously, does each successive drought transform an ecosystem, pushing it towards a new state from which recovery to an original state eventually becomes impossible. Alternatively, are our fauna and flora so well adapted that they can recover comfortably before the next drought strikes? This question is particularly pertinent, considering the prediction that global climate change will result in droughts becoming more severe and possibly more frequent. In addition to sharing experiences of the recent drought, we hoped to identify key data deficiencies in the various research and monitoring projects conducted during the drought, and promote the type of research and monitoring that will allow us to better capture the effects of the next major drought.

\section{Climatology of the 2014-2016 drought}

Johan Malherbe (CSIR) presented an assessment of the drought from a climatological perspective, using nationalscale rainfall interpolations to map where rainfall deficits were most severe. As with major droughts of the recent past, this drought was associated with an El Niño event. It was not as severe as the droughts in the early 1960s, early 1980 s and the early 1990s at a national scale. However, northeastern Mpumalanga, the eastern half of the Free State and northern KwaZulu-Natal appear to have experienced more severe drought than in the previous droughts, with Standardized Precipitation Index values of severe to extreme drought over a 2-year period (Figure 1). The large spatial variation in the severity of drought emerged as a major complication for generalising about the severity and impact of drought at a national scale. Furthermore, droughts vary in their development over time, with some areas experiencing only 1 year of below-average rainfall, and others experiencing 3 years. A key feature of the 2014-2016 drought which distinguished it from former ones was high temperatures, with an unprecedented number of locations experiencing record-breaking monthly mean maximum temperatures during 2015 and 2016. This feature reflects the global pattern of 2016 and 2015 having the highest and second highest global average temperatures on record, respectively.

\section{Impacts on herbivores}

Studies on wildlife and communal livestock populations were presented at the workshop, with die-offs being widely reported. Mortality levels varied with species, functional type and management contexts, especially those that determined the ability of animals to move in response to shortages of food and water. Izak Smit (South African National Parks) explained how management approaches in the Kruger National Park (KNP) have shifted from previous droughts, with the new philosophy promoting natural spatial variability across landscapes to provide a buffer against drought effects. This approach led to the closure of artificial waterholes and removal of fences with neighbouring protected areas since the previous severe drought. As a result, animal distributions prior to the drought were different and forage resources most likely accumulated in areas far from water sources. Large-scale culling of mega-herbivores (buffalo, hippo and elephant) ceased shortly after the 1992/1993 drought, and densities of these species were higher at the onset of the drought, compared to those for previous droughts. However, buffalo mortalities in KNP between 2015 and 2017 were 26\% compared with 48\% during the previous drought (between 1991 and 1993), and less than those reported in fenced private game reserves in the 1982-19831 drought. Carla Staver's (Yale University) analyses of rainfall and grass biomass indicated less severe drought conditions in the north of the park which, combined with larger distances between rivers and other water sources, resulted in greater grass forage reserves. Accordingly, buffalo appear to have migrated from the south of the park to make use of these reserves. In contrast to buffalo, hippo populations in KNP suffered heavy mortality ( $45 \%$ across the four major perennial rivers of the park) with these water-bound animals unable to access areas of forage reserves once they had depleted all forage within walking distance of the large perennial rivers. 


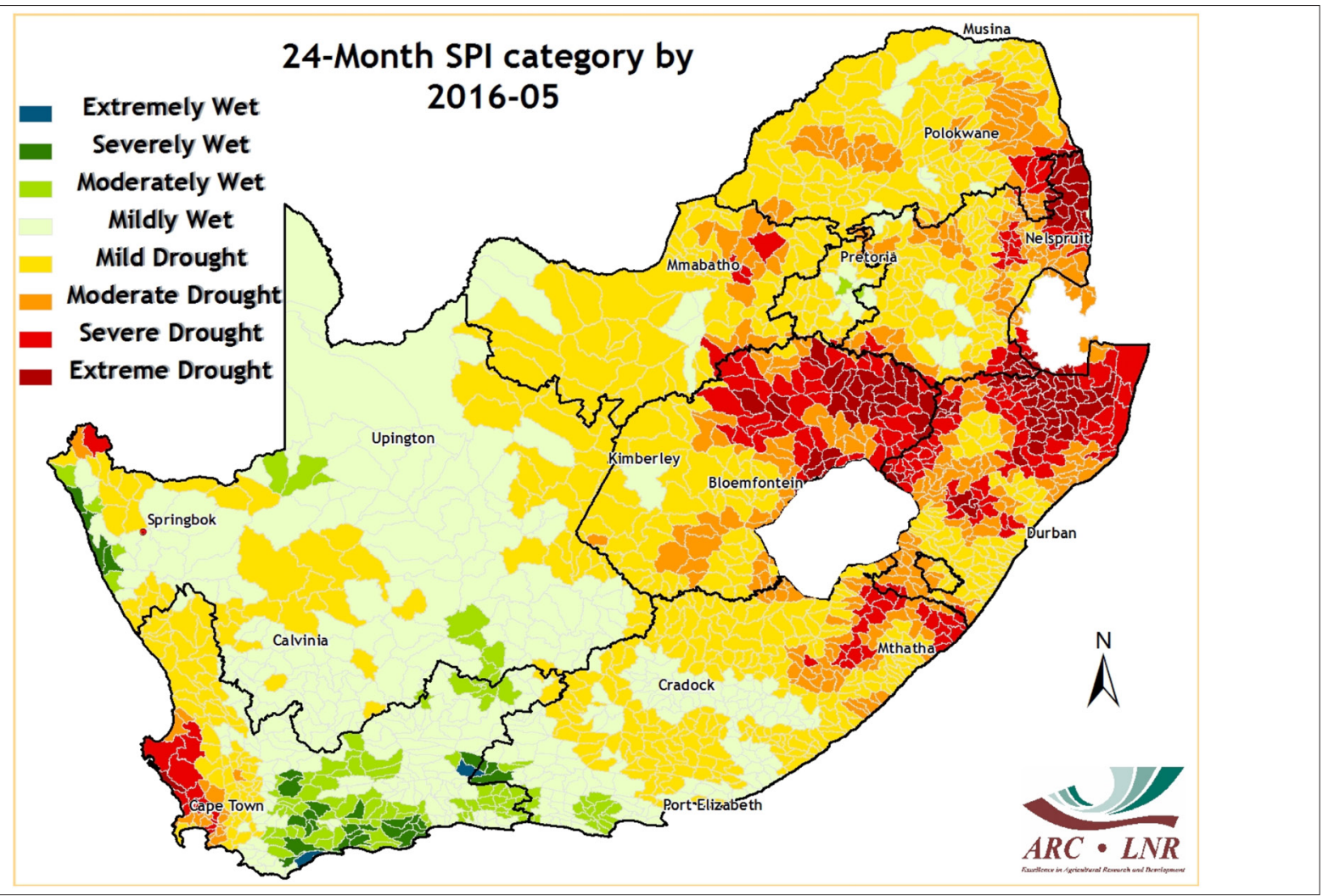

Figure 1: The Standardised Precipitation Index for South Africa over a 2-year period, as of May 2016, indicating which parts of the country experienced the most severe rainfall deficits.

Mike Peel (Agricultural Research Council) highlighted the importance of herbivores being able to move freely during droughts, reporting over $75 \%$ mortality of herbivores in a small, fenced game reserve. Neighbouring private reserves that were open to KNP did not experience the same level of drought mortalities. Researchers working in the Lowveld identified an additional factor that may have mitigated herbivore mortality during the 2014-2016 drought: the timing of rainfall. Rainfall events that occurred in the late summer and early winter produced pulses in grass growth, extending the availability of green forage. Browsing herbivores were seemingly less affected than grazers by the drought. Against expectations, elephant numbers in KNP increased by 13\% between 2015 and 2017. This suggests that the elephant population is still far from being resource limited, and prompted the question of whether drought impacts on the tree layer might have been more pronounced if elephant densities were two or three times higher.

The reliability of livestock data from communal rangelands is problematic because extension officers do not always record livestock numbers accurately, and some livestock owners no longer make use of dipping tanks (where livestock numbers are recorded) nor report stock losses. Estimates of mortality need to take these uncertainties and different methodologies into account. Teddy Mnisi (Department of Agriculture, Limpopo Province) presented the results of monthly monitoring of livestock per municipal district, showing extensive losses and cattle mortality as high as 33\% in the Giyani District. Cobus Botha (Department of Agriculture and Rural Development, KwaZulu-Natal) presented mortality numbers for northern KwaZulu-Natal, for which losses were extensive. Rauri Alcock (Mdukatshani Rural Development Programme) revealed even higher mortality rates from an intensive study of livestock production in KwaZulu-Natal, with losses of $43 \%$ for cattle and $29 \%$ for goats. Losses were heaviest for owners with smaller herds of both cattle and goats, and goat numbers recovered more rapidly than cattle numbers in the year following the drought. Using household-level data, Rauri estimated that the economic losses from livestock across KwaZulu-Natal were more than ZAR10 billion. This amount far exceeds the level of drought relief that government is able to provide. In any case the provision of supplementary feed for cattle, at such a large scale, is not logistically feasible and would result in further degradation of communal rangelands by supporting livestock densities well in excess of local carrying capacities. ${ }^{2}$

\section{Impacts on vegetation}

At all sites where the grass layer was studied, grass production was severely reduced (as expected) but changes in species composition and recovery of production following the drought showed some interesting and unexpected patterns. Many researchers working in the Lowveld identified late season rainfall as a key factor that prevented even more severe reductions in production, and most likely enabled many herbivores to survive the subsequent winter. Longer-term impacts were revealed from monitoring data in conservation areas and commercial livestock farms. These impacts included a reduction in the basal cover of perennial grasses, at both mesic and semi-arid sites, with increases in the abundance of forbs at drier sites, as has been observed for previous droughts. ${ }^{3}$ Dave Thompson (SAEON) presented results from a long-term research site near Satara (central KNP) where drought was particularly severe and where grazing is heavy (relative to KNP in general). Here, grass production was surprisingly resilient, returning to near predrought levels in 2016-2017. Moreover, grass composition showed a distinct change towards more palatable species, with large declines in unpalatable perennials, and an increased abundance of species of highgrazing value (both perennial and annual). A similar trend was presented for long-term research plots in Hluhluwe-iMfolozi Park (KwaZulu-Natal) by Huyam Altayeb (University of Cape Town). These positive results may be offset by greater erosion risk in areas where established unpalatable perennials were lost, although a paucity of data on basal cover and erosion rates makes this difficult to assess. However, it was clear that recovery of primary productivity can occur over years rather than decades, at least in relatively pristine ecosystems. 
Extensive tree deaths from drought have been reported for savannas in the USA and Australia ${ }^{4-6}$, but previous droughts in South Africa appear to have had less impact ${ }^{7,8}$. Less than $1 \%$ of trees had died by the end of 2016 in Hluhluwe-iMfolozi Park, but there was some significant mortality in southern KNP. Research presented by Carla Staver (Yale University) and Tony Swemmer (SAEON) showed that mortality of trees and shrubs was as high as $40 \%$ at some sites within KNP, and even appeared to have resulted in the conversion of open savanna to grassland at a few of these. However such impacts were not widespread, and mortalities only occurred in certain regions and only affected certain species. Overall, it was clear that the drought had not caused widespread tree or shrub mortality across the savanna biome. Whether the drought will result in a pulse of tree recruitment remains to be seen, and established long-term research at a number of sites in the Lowveld provides an opportunity to address this.

\section{Issues emerging}

A number of key research gaps emerged from discussions. It was clear that annual rainfall is not a sufficient metric to properly understand, and predict, the ecological impacts of drought. Other metrics, such as the length of intervals between rainfall events or the incidence of rain in the dry season, also need to be considered, as well as the effect of higher temperatures. Late summer and early winter rainfalls may be particularly relevant for determining how long green forage and browse persist as the dry season progresses, and thus may be a key determinant of herbivore mortality. A better understanding of how El Niño events translate into changes in these variables, at regional scales, is needed to predict the impacts of projected changes in the frequency and magnitude of El Niño events. El Niño development at a monthly timescale may be important in this regard. Spatial variation in rainfall also needs to be measured adequately to properly understand the severity of drought at national or regional scales.

The reliability of the existing data on livestock numbers, especially in communal areas, needs to be assessed. These data are the only means of measuring drought impacts on herbivores over vast areas of the country, as well as quantifying the economic impacts of droughts. Better information on the movement patterns of herbivores (domestic and wild) would enhance our understanding of how different species respond to drought conditions, and enable us to identify forage reserves that are crucial for sustaining populations. ${ }^{2}$ Little is known regarding the potential importance of disease in exacerbating drought-induced mortality of herbivores. Finally, little is known regarding the consequences for rural poor when livestock herds die.

Regarding vegetation data currently available for studying drought impacts, there is a strong geographical bias. There is apparently little data for many of the areas that were severely affected by the 20142016 drought, particularly in the eastern Free State, North West and the Northern Cape Provinces. Most studies of the herbaceous layer presented at the workshop were from semi-arid areas with fertile soils or high rainfall. These are areas that support high herbivore densities, and are thereof of most interest to those concerned about the impact of the drought on herbivore productivity. However, semi-arid areas with infertile soils, such as those underlain by granitic rocks, are far more extensive and make a major contribution to livestock production and eco-tourism at the national scale. Wider geographical coverage of veld and herbivore monitoring is needed before we can generalise drought effects countrywide. Remote sensing of drought impacts could potentially be very useful in extending vegetation monitoring but a key limitation is that dead shrubs and smaller trees cannot be identified, limiting large-scale assessments of mortality. Finally, the mechanisms through which drought kills trees was identified as an important research question for predicting the impacts of more severe droughts in the future.
Trees can starve to death if they are unable to store sufficient carbon as a result of insufficient carbon gain over multiple summers of low rainfall. Alternatively, mortality may be caused by embolisms in the xylem which occur when soil moisture drops below a critical level, in which case a single year (or even a few months) of severe drought could be all that is required. Another gap of 'drought research' identified was whether drought results in a pulse of tree recruitment once good rains return, and studies on post-drought seedling recruitment were agreed to be important. There were no studies presented, or known about by workshop participants, regarding the question of whether drought promotes the spread of alien plants, which Maanda Lighava (University of Venda) raised as a key concern for rural rangelands in the northern Lowveld. Finally, the consequences of past and future vegetation change on stream flow, and thus the supply of fresh water during a drought, is a highly relevant research frontier for South Africa.

\section{Conclusions}

The overall conclusion from the workshop was that the 2014-2016 drought did not have catastrophic impacts on the ecosystems of protected areas and rural rangelands in the northern and eastern parts of the country. Herbivore declines were only severe for a few species, and more so in heavily stocked rangelands and game farms. Extensive protected areas, such as the Kruger National Park, experienced relatively lower herbivore mortality than in previous droughts, and elephants were barely affected. Livestock losses were relatively more severe for owners of small herds, and goat herds appear to have been more resilient than cattle. However, much about the long-term impacts of the drought remain unknown, particularly in terms of long-term changes to vegetation, while links between such changes and negative socio-economic impacts have not been well studied.

\section{Acknowledgements}

The workshop was hosted by SAEON, with funding from the Department of Science and Technology and the National Research Foundation. Workshop participants paid for their own travel.

\section{References}

1. Walker BH, Emslie RH, Owen-Smith N, Scholes RJ. To cull or not to cull: Lessons from a southern African drought. J Appl Ecol. 1987;24:381-401. https://doi.org/10.2307/2403882

2. Illius AW, O'Connor TG. On the relevance of nonequilibrium concepts to arid and semiarid grazing systems. Ecol Appl. 1999;9:798-813. https://doi. org/10.1890/1051-0761(1999)009[0798:0TRONC]2.0.C0;2

3. O'Connor TG. Influence of rainfall and grazing on the compositional change of the herbaceous layer of a sandveld savanna. J Grassl Soc South Afr. 1991;8:103-109. https://doi.org/10.1080/02566702.1991.9648273

4. Carter MG. Effects of drouth on mesquite. J Range Manage Archives. 1964;17:275-276. https://doi.org/10.2307/3895453

5. Fensham RJ, Holman JE. Temporal and spatial patterns in drought-related tree dieback in Australian savanna. J Appl Ecol. 1999;36:1035-1050. https://doi. org/10.1046/j.1365-2664.1999.00460.x

6. Breshears DD, Myers OB, Meyer CW, Barnes FJ, Zou CB, Allen CD, et al. Tree die-off in response to global change-type drought: Mortality insights from a decade of plant water potential measurements. Front Ecol Environ. 2009;7:185-189. https://doi.org/10.1890/080016

7. Gertenbach WPD. Rainfall patterns in the Kruger National Park. Koedoe. 1980;23:35-43. https://doi.org/10.4102/koedoe.v23i1.634

8. O'Connor TG. Impact of sustained drought on a semi-arid Colophospermum mopane savanna. Afr J Range Forage Sci. 1998;15:83-91. https://doi.org/1 0.1080/10220119.1998.9647948 